\title{
Estimation Method of Power System Sufficient for 5-10 years Horizon
}

\author{
Y.Merkurjevs \\ Riga Technical University \\ Latvia
}

\author{
Z. Krishans, I. Oleinikova, A. Mutule \\ Institute of Physical Energetics, \\ Latvia
}

\begin{abstract}
In order to assess sufficiency of Latvian power system, research simulation model has been created. It embraces Latvian, Estonian and Lithuanian systems and parts of Russian and Belorussian power systems. The software LDM-AD has been applied for analysis performance on reliability of transmission network substations and switchgear units, as well as technical and economic analysis of several dynamic development process options observing reliability economic indicators. The researches performed on planning methodology development indicated that system sufficiency estimation for $\mathbf{5}$ and $\mathbf{1 0}$ horizon is not capable to ensure sustainable development strategy. In order to ensure long-term development, entirely different planning methodology and other tools for analysis are required. The planning process shall be sustainable taking into consideration rather long prospective period from 30 to 50 years.
\end{abstract}

Keywords - Power Transmission, Power Generation, Power System planning, Hydroelectric power generation

\section{INTRODUCTION}

In this paper the estimation method of power system sufficient for 5-10 year horizon is considered. This method is used for problems solutions under development of Latvian power system.

The Estimation method is worked out by The Laboratory of Electric Power System Simulation, Institute of Physical Energetics.

\section{Characteristics of LATVIAN Power System}

Baltic IPS includes state owned power systems of Estonia and Latvia and Lithuania, all of which because of historically constructed grid of $330 \mathrm{kV}$ dating from 1960 operate in parallel (on a synchronous AC grid) with the United Power System of Russia and The Power System of Belarus.

The transmission system of the Baltic States is illustrated in the Fig. 1.

The power systems in the three Baltic countries differ considerably. The Estonian system is purely thermal; the Latvian system is based on hydro and thermal technologies, and the Lithuanian system is dominated by nuclear power production. The Table I below illustrates the installed net power capacity in the three countries, represented by diversified types of technologies.

The large differences in the power systems create potential benefits to be gained from international electricity trade between the countries, just as in the Nordic countries.

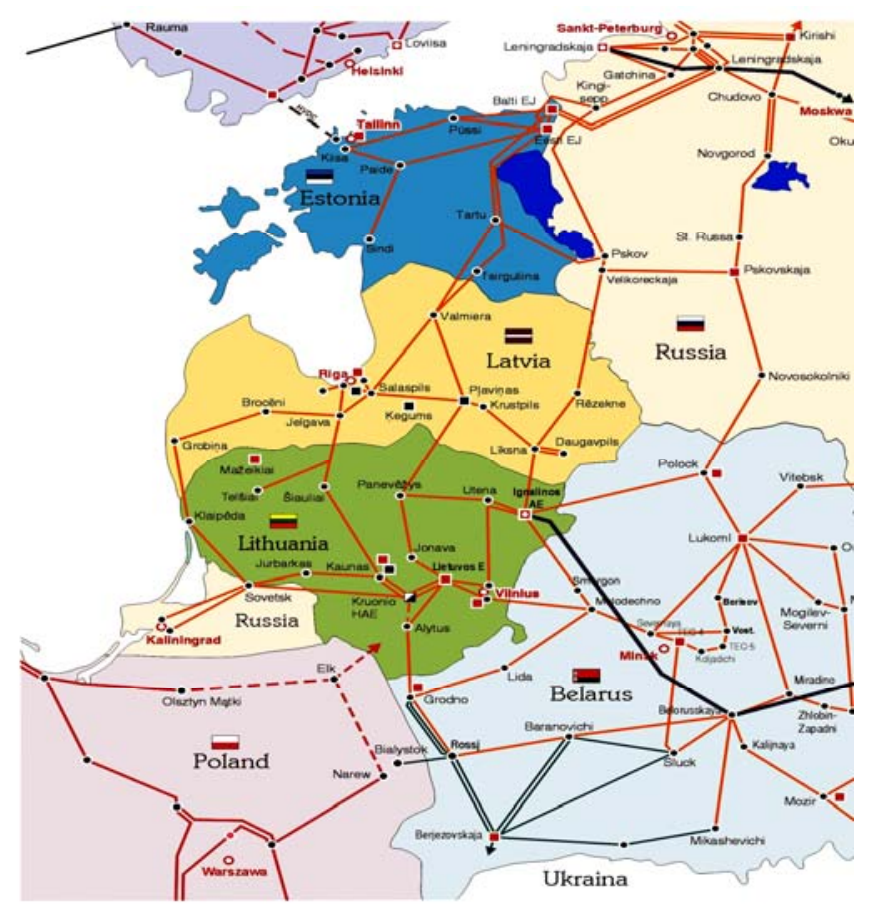

Fig. 1. Transmission network (220 kV and about) of power systems of Baltic countries and connection ties with Russia

TABLE I

INSTALLED NET CAPACITIES 2004 - BALMOREL (MW)

\begin{tabular}{|l|c|c|c|c|}
\hline & Estonia & Latvia & Lithuania & Total \\
\hline Installed capacity & 2324 & 2108 & 5774 & 10206 \\
\hline Nuclear power & 0 & 0 & 2366 & 2366 \\
\hline Thermal power & & & & \\
- condensing & 1960 & 0 & 1448 & 3408 \\
- CHP & 342 & 528 & 1070 & 1940 \\
\hline Hydro power & 0 & 1553 & 90 & 1643 \\
\hline Wind power & 22 & 27 & 0 & 49 \\
\hline HPSPP $_{2}$ & 0 & 0 & 800 & 800 \\
\hline
\end{tabular}

Within the period since 1997 to 2003, the power consumption in Latvia has been rather stable. During the same period in Estonia and Lithuania, the tendency of a slight decrease in the power consumption is observed.

The power consumption today is considerably lower than when the Baltic countries were a part of the former Soviet Union, especially in Lithuania. In 1990, Estonia, Latvia and Lithuania consumed more than 35 TWh in total. The reason for the drop in electricity consumption after 1990 is mainly due to economic recession and restructuring of economy. 
Estonia generates approx. 30\% of the total power generation in the three countries. In Estonia, the power is mainly generated from oil shale. Latvia accounts for $11-18 \%$ of the power generation, which is mainly produced by hydropower and CHP plants. Lithuania accounts for the largest power generation in the three countries, i.e. 48-60\%. The power generation in Lithuania is highly dependent on the country's nuclear power plant, Ignalina. Lithuania also has several thermal oil/gas plants, including thermal combined heat and power plants.

With respect to import and export, Latvia is definitely an importer of electricity while Estonia and Lithuania are net exporters of electricity.

At present, in Baltic countries demand increment rate is 3\% per year and the total balance of electric energy is positive.

Due to liquidation initiation of Ignalina NPP, from the year of 2010, the total capacity of PP in Baltic countries would not be capable to cover the demand.

PSO ordered to elaborate a tool-method "The Estimation Method of Power System Sufficient for 5-10 years Horizon.”

\section{LATVIAN POWER SYSTEM SUFFICIENT ESTIMATION FOR 5- 10 YEARS HORIZON}

In order to assess sufficiency of Latvian power system, research simulation model has been created. It embraces Latvian, Estonian and Lithuanian systems and parts of Russian and Belorussian power systems. The Latvian power system is modelled in the most detailed way, for the rest the model represents the grid $330 \mathrm{kV}$ and the most capacious electric power plants. The topological model of Latvenergo 330 and $110 \mathrm{kV}$ network is worked out, incorporating 160 node points $(110 \mathrm{kV})$ and 25 node points (330 kV), 216 lines $(110 \mathrm{kV})$ and 36 lines $(330 \mathrm{kV}), 14$ substations and 9 electric power plants. $\mathrm{kV})$.

The model of Estonian power system includes 13 lines (330

The model of Lithuanian power system includes 26 lines (330 kV).

The Russian power system is modelled with eleven $330 \mathrm{kV}$ lines, one 500 and five $750 \mathrm{kV}$ lines, that comprises power ring Estonia - St.Peterburg - Moscow - Belarus - Lithuania (Ignalina).

There is assumed in the Research that power balance availability may be provided only in Russia. In order to model this condition in calculation model, the balancing generator node $(\mathrm{Bil})$ is designed nearby Moscow with large power capacity that exceeds capacities of Baltic countries and energy deficit.

The research tool "Latvenergo transmission network and generation system model sufficient estimation for 5 and 10 years Horizon" is being created to ensure the opportunities to:

1) Analyse power systems of Baltic countries as one integrated system unit;

2) To perform comprehensive research of power system, observing technical requirements and economic conditions as well as assessing risk factor.

In order to realise these opportunities for research development process of transmission network, and generators system, the software LDM-AD has been applied for analysis performance of operation reliability of transmission network substations and switchgear units, as well as technical and economic analysis of several dynamic development process options observing reliability economic indicators [1].

330 and $110 \mathrm{kV}$ estimation of transmission network reliability and security:

1) Estimate reliability of transmission network;

2) Calculate disconnection time of electric power supply;

3) Ensure opportunity to estimate reliability of transmission network scheme if one or two lines are disconnected including if one line is under scheduled maintenance and tripping of the second line occurred;

4) Observe lines disconnection for scheduled maintenance if the line is radial.

It would helpful also to perform the following:

- Research model's prompt input and operative its adjustment;

- $\quad$ Set-up of development option;

- Electric calculations of steady (normal) and postemergency operation states;

- Analysis of electric power plants;

- Economic benchmarking (comparison) of options;

- Risk analysis of information under uncertainty conditions.

The structure of LDM-AD is represented in Fig. 2.

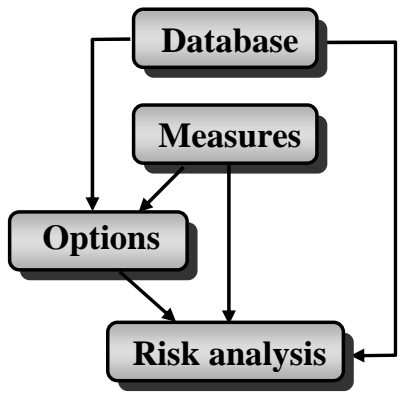

Fig. 2. Block scheme of LDM-AD

Let's review the major models in a more detailed way[2].

Model Measures - forming model of development events. The modelled events are used for searching of the optimal option with simulation method (Simm).

Model Simm. By this model applying development measures, the user forms development options and performs its technical economic analysis. The model Simm can be used for simple optimisation assignment, direct solution or for complex assignment on optimisation range reduction.

Model Risk - risk matrica formation model, applying Options. The presented sets of development states can be selected before risk analysis and can be supplemented during risks analysis based on the obtained results. The optimal option is selected according to minmax R criterion.

The forecast is characterised by:

- Forecast probability factor $q$,

- Load increase factor by steps,

- Losses cost elevation factor by steps,

- Interest percent rate,

- Inflation percent rate for investments and costs in network,

- Operation costs, 
- $\quad$ Capacity of new Power Plant.

In order to simulate electric power systems with hydro power plants, cogeneration power plants specialised load and electric power energy operation state model has been created. Load and power plants output is simulated by 12 states per year; each state corresponds to one month and load or generation (output) is represented by monthly average power capacity. The Consumer may have diversified load curves (up to 5 load groups), but there is the individual generation schedule for each generator) (see Table II).

TABLE II

MONTHLY SCHEDULES ON CONSUMPTION AND ELECTRIC POWER PLANTS GENERATION (OUTPUT)

\begin{tabular}{|c|l|c|c|c|c|}
\hline No. & Month & Tre, hours/year & P1 & H1 & C1 \\
\hline 1 & January & 730 & 0.97 & 0.17 & 0.5 \\
\hline 2 & February & 730 & 0.88 & 0.25 & 0.44 \\
\hline 3 & Mart & 730 & 0.97 & 0.46 & 0.34 \\
\hline 4 & April & 730 & 0.76 & 0.74 & 0.21 \\
\hline 5 & May & 730 & 0.81 & 0.25 & 0.13 \\
\hline 6 & June & 730 & 0.71 & 0.15 & 0 \\
\hline 7 & July & 730 & 0.77 & 0.11 & 0 \\
\hline 8 & August & 730 & 0.76 & 0.09 & 0 \\
\hline 9 & September & 730 & 0.83 & 0.09 & 0 \\
\hline 10 & October & 730 & 0.91 & 0.11 & 0.1 \\
\hline 11 & November & 730 & 0.96 & 0.24 & 0.33 \\
\hline 12 & December & 730 & 1 & 0.39 & 0.36 \\
\hline
\end{tabular}

P1 - average monthly consumption for the first group in relative units;

H1 -average monthly generation (output) in hydro power plant in relative units;

C1 - average monthly generation (output) in cogeneration power plant in relative units.

As far the power systems of Baltic countries are under shortage conditions of capacity and energy, the software programme $L D M-A D$ is supplemented in such a way that for each state at any development step and option all power systems capacities and import/export may be extracted. Calculation example is presented in Tables III and IV.

TABLE III

NUMBER OF OVERLOADED 110 AND 330 KV LINES IN LATVIAN POWER SYSTEM

\begin{tabular}{|c|c|c|c|c|c|c|}
\hline \multirow{4}{*}{$\begin{array}{l}\text { Name } \\
\text { State } \\
\end{array}$} & \multicolumn{6}{|c|}{ Number of overloaded lines } \\
\hline & \multicolumn{4}{|c|}{ Normal } & \multicolumn{2}{|c|}{ Post emergency } \\
\hline & \multicolumn{2}{|c|}{2011} & \multicolumn{2}{|c|}{2016} & \multirow{2}{*}{\begin{tabular}{|l|}
2011 \\
330 \\
\end{tabular}} & \multirow{2}{*}{\begin{tabular}{|c|}
2016 \\
330 \\
\end{tabular}} \\
\hline & 110 & 330 & 110 & 330 & & \\
\hline January & 0 & 0 & 0 & 1 & 0 & 1 \\
\hline February & 0 & 0 & 0 & 0 & 0 & 0 \\
\hline Mart & 0 & 0 & 0 & 0 & 0 & 0 \\
\hline April & 0 & 2 & 0 & 0 & 2 & 0 \\
\hline May & 0 & 0 & 0 & 0 & 0 & 0 \\
\hline June & 0 & 0 & 0 & 0 & 0 & 0 \\
\hline July & 0 & 0 & 0 & 0 & 0 & 0 \\
\hline August & 0 & 0 & 0 & 0 & 0 & 0 \\
\hline September & 0 & 0 & 0 & 0 & 0 & 0 \\
\hline October & 0 & 0 & 0 & 0 & 0 & 0 \\
\hline November & 0 & 0 & 0 & 0 & 0 & 0 \\
\hline December & 0 & 0 & 0 & 1 & 0 & 1 \\
\hline Total: & 0 & 2 & 0 & 2 & 2 & 2 \\
\hline
\end{tabular}

TABLE IV

ENERgy BALANCE IN LATVIAN POWER SySTEM AND BALTIC STATES

\begin{tabular}{|l|r|r|r|r|}
\hline \multicolumn{1}{|c|}{ Name } & \multicolumn{3}{c|}{ Energy balance* } \\
\hline \multicolumn{1}{|c|}{ State } & \multicolumn{2}{|c|}{ Latvia } & \multicolumn{2}{c|}{ Baltic area } \\
\hline & $\mathbf{2 0 1 1}$ & \multicolumn{1}{c|}{$\mathbf{2 0 1 6}$} & $\mathbf{2 0 1 1}$ & \multicolumn{1}{c|}{$\mathbf{2 0 1 6}$} \\
\hline January & -513 & -787 & -622 & -149 \\
\hline February & -347 & -593 & 40 & 669 \\
\hline Mart & -138 & -396 & 249 & 875 \\
\hline April & 488 & 290 & 1088 & 2727 \\
\hline May & -326 & -527 & 1083 & 2034 \\
\hline June & -321 & -498 & 1397 & 2449 \\
\hline July & -455 & -645 & 1124 & 2128 \\
\hline August & -468 & -657 & 1115 & 2121 \\
\hline September & -565 & -772 & 759 & 1682 \\
\hline October & -633 & -870 & 161 & 915 \\
\hline November & -524 & -780 & -98 & 544 \\
\hline December & -429 & -701 & -284 & 264 \\
\hline \multicolumn{1}{|c|}{ Total: } & & & & \\
\hline
\end{tabular}

* - ,„” - import, MW; ,"+" - export, MW

The information represented in the tables provides an opportunity in a comprehensive way to estimate diversified development options in regard to power systems sufficiency point. The research performed has proved that:

1. Several thermal power stations (of basic load) shall be built in Latvia.

2. In order to improve reliability and security of electric power supply in Latvia more new $330 \mathrm{kV}$ lines shall be constructed.

3. Unfortunately, the undertakings suggested would neither provide sufficient capacity of transmission network of Latvian power system in 2011 nor in 2016. Even all the suggested measures or undertakings be realised, the Latvian power system is still capacity and energy deficit system, as well as there are overloaded lines in network of $330 \mathrm{kV}$.

4. Commissioning of new modern Ignalina NPP in 2016 would solve the problem concerning full independence of Baltic States from Russian power system (see Table V).

TABLE V

ENERgy BALANCE OF POWER SYSTEMS OF BALTIC STATES IN 2016

\begin{tabular}{|l|r|}
\hline \multicolumn{1}{|c|}{ Options } & \multicolumn{1}{c|}{ TWh } \\
\hline Excl. Ignalina NPP & -2.33 \\
Incl. Ignalina NPP & +13.65 \\
\hline
\end{tabular}

\section{ANTICIPATED EXPENSES FoCUSED ON IMPROVEMENT OF OPTIMISATION METHODS OF TRANSMISSION NETWORK AND ENERGY SOURCES DEVELOPMENT}

The researches performed on planning methodology development indicated that system sufficiency estimation for 5 and 10 horizon is not capable to ensure sustainable development strategy; in the result of these methods the decisions may be taken only for short-time undertakings or measures to prevent unreliable and non-admissible state in the system [3, 4]. In order to ensure long-term development, entirely different planning methodology and other tools for analysis are required. The planning process shall be 
sustainable taking into consideration rather long prospective period from 30 to 50 years.

Economic analyses determine economic life cycle of the object, in networks - 20-25 years. Efficiency function is calculated to all estimation periods $T$. Under the information uncertainty conditions decision making is acceptable only for the nearest future (approx. 5 years forward). These time intervals are represented as decision-making period $t d<T$ (see Fig. 3).

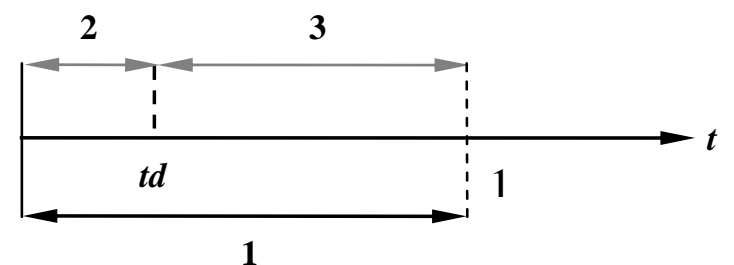

Fig. 3. Development process. 1 - estimation period; 2 - decision-making (planning) period; 3 - adaptation period

Information about development period is uncertain; therefore for decision-making the regular decision adaptation is necessary.

At present the specialists of the Laboratory of Electric Power System Simulation are working to create the respective analysis instrument or tool, anticipated process block-scheme is presented in Fig. 4.

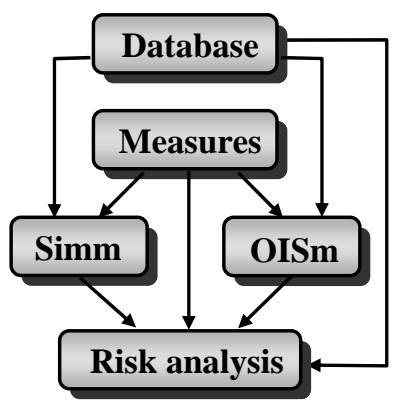

Fig. 4. Block scheme of sustainability analysis model

Model structure of sustainability analysis differs from LDM- $A D$ structure (see Fig. 2), the model integrates optimisation model which is capable to perform optimisation for 50 years perspective.

OISm - dynamic optimisation model, utilising optimal initial state method. Optimisation range is formed by formed measures (see Fig. 4), OISm structure is presented in Fig. 5.

The main parts of model OISm are:

: = - direct cycle according to development steps;

Omega ( $t)$ - optimal initial state at the collection step $t$ model; total omega $(t)$ is input information set omega $(t+1)$ searching;

Options K - more optimal development options formation, applying OIS; in total omega $(t), t=t m,(t m-1) \ldots 1$.

The output of model OISm is the same as in model Simm.

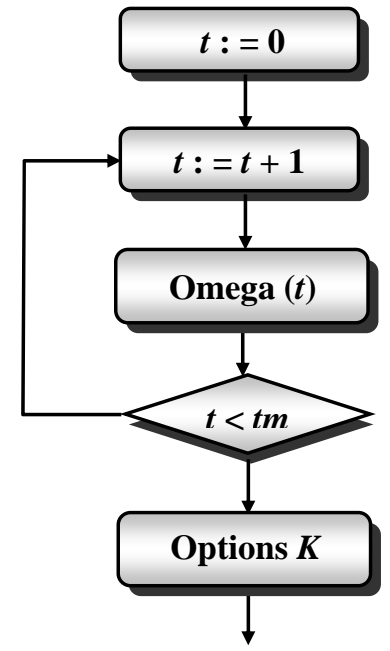

Fig. 5. Structure of model OISm

Optimization selects the competitive options group (up to 10 options). Optimization consists of two sub-blocks: 1) set up of alternative actions and 2) dynamic optimization. Optimization takes place under the determined information average forecast.

In order to observe uncertainty after Optimization - Risk analysis shall be applied. Optimization is performed by the OISm.

In order to create software on sustainability strategy analysis it is required:: 1) to increase number of optimisation steps from 10 to 302 ) to improve estimation methods of operation reliability to eliminate calculation time; 3) to work out assessment methods of ecological problems; 4) to elaborate estimation methods on simplified system stability; 5) to create IT analysis methods on connection to information sources - load measurements etc.

This work has been supported by the European Regional Developmental Fund project at Riga Technical University.

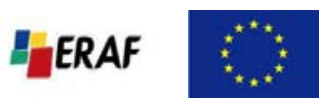

\section{REFERENCES}

[1] Z. Krishans, L. Oleinikova, A. Mutule. "Latvian Dynamic Model (LDM) Family for Network Development Optimization,” presented at the $2^{\text {nd }}$ International Scientific Symposium "Elektroenergetika”, Stará Lesná, Slovak Republic, 2003, pp. 200-201.

[2] Z. Krishans, L. Oleinikova, A. Mutule, J. Runcs. "Dynamic Simulation Method for Transmission and Distribution Planning.” SWEAS Transactions on Systems and Control, Issue 1, Volume 1, 2006, pp. 155-160.

[3] Z. Krishans, A. Kutjuns, I. Oleinikova. "Method of Transmission Power Networks Reliability Estimation." "Energétika un elektrotehnika”, Volume 1, 2006, Riga: RTU, pp. 13-18.

[4] J.M. Smith. "Evolution and The Theory of Games". Cambridge, UK, Cambridge University Press, 1982. 


\section{BIOGRAPHIES}

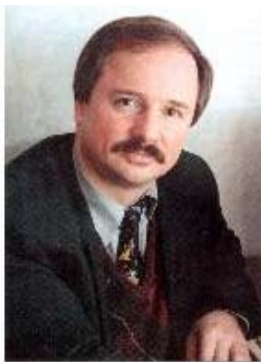

Yuri Merkuryrev is Habilitated Doctor of Engineering, Professor of the Institute of Information technology at Riga Technical University, Head of the Department of Modelling and Simulation. His professional interests include a methodology and practical implementation of discrete-event simulation, supply chain modelling and management, and education in the areas of modelling, simulation and logistics management. He is Programme Director of the Master-level curriculum "Industrial Logistics Management" at RTU. Has a wide experience in performing research and educational projects in the simulation area, at both national and European levels, and regularly participates in organising international conferences in the simulation area. He was General Chair of the 2005 European Conference on Modelling and Simulation held in June, 2005 in Riga, Latvia. Prof has about 200 scientific publications, including 4 books. He is a Board member of the EU Council of the Society for Modeling and Simulation International, President of the Latvian Simulation Society, and Board member of the Latvian Transport Development and Education Association.

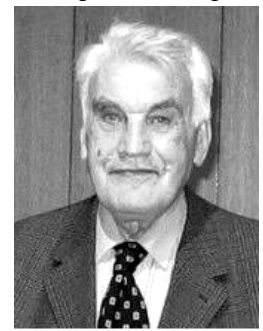

Zigurds Krishans was born in Riga, Latvia, on May 1, 1930. He graduated as Civil Electrical Engineer from Latvian State University (1954) and received his Ph.D. degree (1961) from Kiev Polytechnical Institute, USSR and Doctor of Sciences (1984) from Moscow Power Engineering Institute, USSR. He is a Professor (1994) at the Institute of Physical Energetics and Riga Technical University, and the Head of the Laboratory of Electric Power System Simulation (1969) at the Institute of Physical Energetics. Prof. is the Vice President (1992) of the Baltic Association of Electric Power System Researchers. His main research interests include Methods for Mathematical Modelling of Electrical Networks and Systems; Methods for Development of Power Systems Planning; Dynamic Optimisation Methods and Decision Systems. Prof. is author of more than 210 papers, including 11 books.

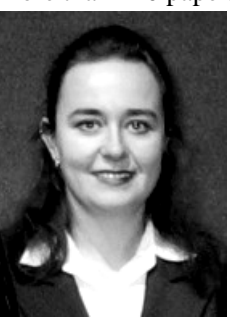

Irina Oleinikova was born in Riga, Latvia, on September 16, 1974. She received the BSc, E.E., MSc and Dr.sc.ing. degrees from the Riga Technical University, in 1994, 1995, 1997 and 2000 respectively. She is senior researcher in the Laboratory of Electric Power System Simulation at the Institute of Physical Energetics. Her main research interests include Methods for Mathematical Modelling of Electrical Networks and Systems; Methods for Development of Power Systems Planning; Dynamic Optimization Methods and Decision Systems. She is author of 70 papers.

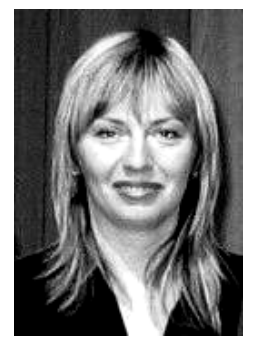

Anna Mutule was born in St.Petersburg, Russia, on December 16, 1975. She received the BSc, MSc and Dr.sc.ing. degrees from the Riga Technical University, in 1999, 2002 and 2005 respectively. She is senior researcher in the Laboratory of Electric Power System Simulation at the Institute of Physical Energetics. Her main research interests include Methods for Mathematical Modelling of Electrical Networks and Systems; Methods for Development of Power Systems Planning; Dynamic Optimisation Methods and Decision Systems. She is author of 38 papers. 